\title{
O EXERCÍCIO DA INTEGRALIDADE EM UMA EQUIPE DA ESTRATÉGIA SAÚDE DA FAMÍLIA: SABERES E PRÁTICAS
}

\author{
Fernanda Carlise Mattioni ${ }^{1}$, Maria de Lourdes Denardin Budó², Maria Denise Schimith ${ }^{3}$
}

\begin{abstract}
${ }^{1}$ Mestre em Saúde Pública. Especialista em Saúde da Secretaria Estadual de Saúde do Rio Grande do Sul. Enfermeira do Serviço de Saúde Comunitária do Grupo Hospitalar Conceição. Rio Grande do Sul, Brasil. E-mail: fcmattioni@yahoo.com.br

${ }^{2}$ Doutora em Enfermagem. Professora Associado do Departamento de Enfermagem e do Programa de Pós-Graduação em Enfermagem da Universidade Federal de Santa Maria (UFSM). Rio Grande do Sul, Brasil. Email: lourdesdenardin@gmail.com

${ }^{3}$ Mestre em Enfermagem. Professora Assistente do Departamento de Enfermagem da UFSM. Rio Grande do Sul, Brasil. E-mail: ma.denise@hotmail.com
\end{abstract}

\begin{abstract}
RESUMO: O Sistema Único de Saúde preconiza a integralidade como diretriz orientadora das práticas de cuidado em saúde. Apesar de avanços na saúde coletiva, nota-se dificuldade em exercitá-la no cotidiano dos serviços de saúde. Objetivou-se conhecer as práticas de cuidado de uma equipe de Estratégia Saúde da Família e sua relação com a integralidade. Trata-se de pesquisa descritiva e qualitativa. Os dados foram coletados por meio de observação participante, entrevistas e consulta em documentos, os quais foram analisados segundo a análise temática. Foram encontrados os seguintes sentidos da integralidade: como percepção das diferentes dimensões e da complexidade dos usuários; como articulação das formas de cuidar; e como identificação e atendimento das necessidades em saúde; como esforço da equipe em produzir saúde; como cuidado a grupos específicos. A partir da análise dos dados, afirma-se a necessidade de construir novas práticas, voltadas para a reorientação do modelo assistencial, visando tornar possível o exercício da integralidade.

DESCRITORES: Assistência integral à saúde. Saúde da família. Equipe interdisciplinar de saúde.
\end{abstract}

\section{EXERCISING INTEGRALITY IN A FAMILY HEALTH STRATEGY TEAM: KNOWLEDGE AND PRACTICES}

\begin{abstract}
Brazil's National Health Care System (Sistema Único de Saúde) advocates integrality as a guideline for its health care practices. Despite advances in public health, one notes difficulties in exercising integrality in the daily practice of health services in Brazil. This research aimed to better understand care practices in a Family Health Strategy health care team and their relationship with integrality. It is a qualitative and descriptive study. Data was collected using the research strategies of participant observation, interviews, and documental investigation and then submitted to thematic analysis. The following meanings of integrality were found: as a perception of the users' different dimensions and complexities; as an articulation of the ways of care; as an identification and meeting of health needs; as effort from the health care team to produce health; as care to specific groups. Data analysis affirms the need to construct new practices geared to reorienting the care model in order to make it possible to exercise integrality.
\end{abstract}

DESCRIPTORS: Comprehensive health care. Family health. Patient care team.

\section{EL EJERCICIO DE LA INTEGRALIDAD EN UN EQUIPO DE ESTRATEGIA DE SALUD FAMILIAR: CONOCIMIENTOS Y PRÁCTICAS}

\begin{abstract}
RESUMÉN: El Sistema Único de Salud recomienda la integralidad como línea orientadora de las prácticas de cuidado en salud. A pesar de los avances en la salud colectiva, hay dificultades para ejercerla en el cotidiano de los servicios de salud. El objetivo fue el de conocer las prácticas de cuidado de un equipo de Estrategia de Salud Familiar y su relación con la integralidad. Se trata de una investigación descriptiva y cualitativa. La recolección de los datos se hizo a través de la observación participante, de entrevistas y consulta a documentos, los cuales se analizaron según el análisis temático. Se encontraron los siguientes sentidos de la integralidad: como percepción de las diferentes dimensiones y de la complejidad de los usuarios; como articulación de las formas de cuidar; como identificación y atención a las necesidades en materia de salud; como esfuerzo del equipo para producir salud; como cuidado a grupos específicos. A partir del análisis de los datos, se hace necesario construir nuevas prácticas dirigidas a la reorientación del modelo asistencial con el fin de hacer posible el ejercicio de la integralidad.
\end{abstract}

DESCRIPTORES: Atención integral de la salud. Salud de la familia. Grupo de atención al paciente. 


\section{INTRODUÇÃO}

O Sistema Único de Saúde (SUS), criado em 1988, proporcionou muitos avanços no setor saúde. Dentre as diretrizes que o estruturam, a integralidade da atenção compreende uma estratégia de reorientação das práticas de cuidado, sendo preconizada no cotidiano dos serviços de saúde. Essa diretriz surgiu no contexto de lutas e mobilização pela saúde, travadas na década de 1980, como direito de todo cidadão brasileiro, que se concretizou legalmente com a criação do SUS. ${ }^{1}$ Segundo o artigo 198 da Constituição Federal de 1988, está previsto, entre outras diretrizes, o "atendimento integral, com prioridade para as atividades preventivas, sem prejuízo dos serviços assistenciais". 2:50

A integralidade, ao longo da construção do SUS, passou a ser assumida como prática social e prática política, o que torna necessário conhecer e compreender o modo de vida das pessoas a fim de viabilizar o cuidado integral. ${ }^{3}$ A Atenção Básica consiste no espaço de cuidado mais próximo da vida dos usuários do SUS, pois tem a territorialização como ponto de partida para a organização dos serviços de saúde. O território no qual o serviço de saúde está inserido é um espaço vivido no qual são travadas as relações sociais que dão sentido as características locais. ${ }^{4} \mathrm{~A}$ proximidade estabelecida entre a equipe de saúde e os usuários denota a possibilidade de apreensão de seus modos de viver e perceber o mundo. Os profissionais podem valer-se desse espaço para identificar as necessidades em saúde da população e contemplar um dos tantos sentidos da integralidade: a organização dos serviços de saúde em função das necessidades evidenciadas. $^{5}$

Apesar de visualizarmos avanços que, minimamente, garantem cuidados básicos em saúde, os recursos financeiros escassos e os problemas de organização e gestão impedem que as ações realizadas atendam satisfatoriamente à demanda social para o setor saúde. Além disso, a prática da integralidade depende da sensibilidade e disponibilidade dos profissionais para compreenderem os diferentes aspectos que influenciam o estado de saúde do ser humano de quem estão cuidando. ${ }^{6}$ Estes profissionais precisam ter conhecimento técnico e habilidade política para possibilitar o desenvolvimento de ações que viabilizem a resolução compartilhada dos problemas apresentados pelo usuário. A estrutura socioeconômica vigente também impõe limitações ao exercício da integralidade. Na ordem estabelecida, a situação de pobreza e miséria de muitos, a rotina exaustiva de trabalho e o stress gerado pela dinâmica de vida acelerada são fatores condicionantes do estado de saúde das pessoas. ${ }^{1}$ A qualidade de vida dos usuários depende da amplitude do olhar dos diferentes serviços e setores, dentre eles o setor saúde, para as iniquidades sociais, bem como a capacidade de articulação do Estado, na perspectiva de possibilitar o acesso a bens e serviços necessários à vida, previstos na CF/1988 como direitos sociais. Frente à problemática apresentada, este artigo tem como objetivo descrever as práticas de cuidado de uma equipe da Estratégia Saúde da Família e sua relação com a integralidade.

\section{Método e procedimentos de pesquisa}

O presente estudo foi realizado com uma equipe da Estratégia Saúde da Família (ESF) de um município localizado na Região Sul do Brasil, implantada em maio de 2004. Em razão do grande número de pessoas residentes na área de abrangência, funcionavam duas equipes de ESF na mesma Unidade. Essas equipes assistiam cerca de 2.350 famílias, perfazendo um total de mais de 11 mil pessoas, extrapolando assim o número máximo de quatro mil pessoas atendidas por equipe, como é previsto pelo Ministério da Saúde. ${ }^{7} \mathrm{O}$ universo empírico da pesquisa foi composto pelos trabalhadores das equipes de ESF, das quais faziam parte: uma médica, duas enfermeiras, duas técnicas de enfermagem, uma dentista, uma auxiliar de consultório dentário, um recepcionista e seis Agentes Comunitários de Saúde.

A coleta de dados foi realizada no período de fevereiro a junho de 2008, por meio de observação participante, entrevistas e análise documental. Estas técnicas foram escolhidas por serem condizentes com o objetivo do estudo: conhecer as práticas de cuidado de uma equipe de Estratégia de Saúde da Família e o exercício da integralidade por meio destas práticas. As entrevistas foram constituídas no intuito de investigar as noções dos profissionais acerca da integralidade; a percepção acerca do exercício ou não da integralidade nas práticas de cuidado da equipe; os fatores capazes de influenciar o exercício da integralidade e as atitudes da equipe que poderiam viabilizar o exercício da integralidade em suas práticas de cuidado. A observação participante foi utilizada na coleta dos dados a fim de obter informações acerca das práticas de cuidado realizadas pela equipe, em seu cotidiano de trabalho. O referido método tem como base 
a ideia de que os comportamentos humanos só podem ser devidamente compreendidos e explicados se tomarmos como referência o contexto social onde eles atuam. Durante os cinco meses de coleta de dados a pesquisadora observou as diferentes práticas de cuidado realizadas pela equipe. Procurou-se vivenciar os fluxos estabelecidos pela equipe de saúde, o caminho percorrido pelo usuário na busca por cuidados e o retorno da equipe frente a esta busca. Neste percurso, foram observadas as filas para a marcação de consultas, os diálogos na recepção, as consultas médicas e de enfermagem, as atividades de educação em saúde, entre outros momentos de encontro dos profissionais com os usuários. A partir deste olhar foi possível analisar as relações estabelecidas no campo de estudo e buscar os significados acerca das práticas observadas. ${ }^{8}$

As entrevistas semiestruturadas realizaramse na Unidade de Saúde da Família (USF) e os documentos analisados foram os prontuários das famílias. Os dados obtidos por meio da observação participante foram registrados em um diário de campo e as entrevistas gravadas em arquivos do tipo mp3, em CDs, e posteriormente transcritas. A análise se realizou por meio da análise temática, constituída por três fases: a pré-análise, a exploração do material e o tratamento dos resultados obtidos e interpretação. ${ }^{9}$ Durante a leitura exaustiva dos dados buscou-se identificar os temas significativos ao objeto de estudo, levando em consideração os dados obtidos nas três fontes, a fim de definir seus pontos de aproximação e suas incongruências. $\mathrm{Na}$ fase seguinte da análise os dados foram agrupados de acordo com a convergência dos temas, sendo ressaltados, durante a interpretação, os pontos comuns e as incongruências presentes nos dados obtidos por meio das entrevistas, observação participante e documentos.

Este estudo foi aprovado pelo Comitê de Ética em Pesquisa da UFSM, com o Protocolo de número 0203.0.243.000-07, em 07/02/08. Na assinatura do Termo de Consentimento Livre e Esclarecido, os participantes foram informados sobre a pesquisa e os preceitos éticos que a permeiam. Para manter o anonimato dos sujeitos, foram utilizados códigos numerados de acordo com a ordem de realização das entrevistas, nos quais TS significa Trabalhador da Saúde. No decorrer de todo o processo de estudo, foram observadas as normas da Resolução $n^{\circ}$ 196/96 do Conselho Nacional de Saúde, MS, que regem as pesquisas envolvendo seres humanos. ${ }^{10}$

\section{RESULTADOS}

A partir da análise qualitativa dos dados, emergiu a categoria empírica - Cuidado integral: observações acerca de saberes e práticas. Essa categoria originou cinco subcategorias, que serão apresentadas a seguir, no intuito de identificar seus significados.

\section{A integralidade como percepção das diferentes dimensões e da complexidade dos usuários}

A concepção dos profissionais acerca da integralidade em saúde refere-se à noção do usuário como um ser dotado de diferentes dimensões, integradas entre si. Durante a vivência com a equipe de ESF, várias situações apresentaram percepções ampliadas dos usuários. Elas foram ilustradas durante a realização de uma consulta médica de pré-natal, na qual observou-se a preocupação em relevar os diferentes aspectos da vida da gestante e não apenas suas peculiaridades biológicas. $\mathrm{Na}$ ocasião, observou-se que o trabalhador responsável pelo referido cuidado possuía entendimento da influência de todas as questões investigadas, que abordavam não só o caráter biológico, mas psicológico, socioeconômico e cultural, e interferiam diretamente na saúde da mulher e do feto. Essa observação é ratificada pelas falas dos profissionais: [...] tu ver o paciente como um todo, dentro de um contexto, o contexto que está inserido, dentro da comunidade, dentro da família, é procurar não olhar só a doença [...] (TS01); [...] assistir o usuário, sua família e comunidade [...] (TS02); [...] é atender o indivíduo na sua totalidade, no máximo possível [...] (TS03); [...] É enxergar o indivíduo não apenas como um ser biológico que tem uma patologia e sim um ser complexo [...] (TS04).

Uma prática de integralidade próxima à discussão acima realizada diz respeito à abordagem das diferentes dimensões que compreendem o ser humano. Esta noção de integralidade propõe a superação de um modelo de atenção à saúde caracterizado como "cartesiano", que divide e reduz os usuários aos seus aparelhos biológicos. A integralidade ganha espaço nas práticas cotidianas dos trabalhadores da saúde, que podem exercitá-la na medida em que respondam às necessidades das pessoas que os procuram. ${ }^{6}$

Ao analisar alguns prontuários, percebeu-se que, na maior parte das evoluções, sobressaíam-se os aspectos biológicos, principalmente sintomas físicos e/ou informações relacionadas ao sistema 
fisiológico do qual se originou a queixa: [...] mastalgia [algia em mamas]. Parto há dois anos. Não amamenta. G:2 P:2 A:0. Toma ACO. CP Atrasado. Mamas: normais. [...] (Prontuário).

Embora tenha sido observado que, em muitas situações outros aspectos, para além das questões biológicas, tenham sido abordados nas consultas com trabalhadores da saúde, como os referentes às relações sociais do usuário atendido, as condições de vida, cultura, afetividade, entre outros fatores, as informações provenientes desses aspectos dificilmente são registradas nos prontuários, talvez por serem consideradas, ainda, secundárias.

Em muitos momentos privilegiava-se a realização de um número elevado de consultas médicas em detrimento de ações de prevenção e promoção da saúde. Nessas consultas, o objetivo principal restringia-se à resolução dos sintomas que o usuário apresentava, não sendo considerados outros sistemas biológicos do organismo e, muito menos, outros aspectos referentes às suas vidas.

Na ativação do princípio da integralidade, existe uma situação paradoxal no campo da saúde. Há contradições no cotidiano dos serviços, principalmente no que tange aos trabalhos realizados por equipes multiprofissionais, diante da exigência de processos inter/transdisciplinares. ${ }^{11}$ A partir dessa afirmação, compreende-se o porquê do exercício da integralidade em práticas isoladas na equipe de saúde. Isso ocorre em função da limitação em se realizar práticas de cuidado de maneira integrada por todos os trabalhadores da equipe, pois estes possuem características de formação distintas, pela especificidade de cada núcleo profissional e, também, por demonstrarem diferentes níveis de imersão na diretriz da integralidade.

Com relação à complexidade dos usuários, destaca-se uma situação na qual uma usuária procurou a USF no intuito de buscar ajuda para seu marido, usuário de álcool, e para seu filho, usuário de "cola de sapateiro" e maconha, e que havia abandonado a escola. Frente a essa situação, os trabalhadores da equipe de ESF procuraram conhecer o contexto em que essas pessoas viviam e as relações sociais nele estabelecidas. Identificouse que se tratava de uma família inserida em comunidade de baixa renda, na qual o marido trabalhava, eventualmente, como carregador de sacos de grãos, e o adolescente, seu enteado, não possuía uma boa relação com ele. Nota-se que essa mulher não procurava ajuda apenas para o marido e o filho, mas também para ela e seu filho menor, pois o ambiente familiar encontrava-se abalado em razão dos conflitos gerados pela dependência química de dois de seus integrantes. Esses aspectos revelaram que a doença apresentada (dependência química) pode ter sua origem nos conflitos presentes nas relações sociais, provenientes da complexidade desses usuários e do contexto no qual estavam inseridos. Frente a estas relações sociais o processo de intervenção com famílias não pode ser pensado apenas no âmbito do atendimento direto. É necessário vislumbrar outras possibilidades para o trabalho com famílias, tais como a observação de espaços de proposição, articulação e avaliação de políticas sociais e de organização e articulação de serviços como campos fundamentais de intervenção na área da família. ${ }^{12} \mathrm{~A}$ equipe de ESF percebeu que apenas suas ações, isoladas, não seriam eficazes na solução do problema. Procuraram, assim, os serviços de psicologia e assistência social, capazes de agregar mais elementos para o cuidado demandado pela situação. Esses trabalhadores formaram uma estrutura de ações conjuntas, procurando atuar a partir de diversas frentes, de maneira a problematizar também o contexto onde os usuários estavam inseridos, potencializando a eficácia de suas ações.

Considerando a demanda em saúde dessa família, pode-se realizar uma análise quanto à complexidade dos indivíduos. É preciso, inicialmente, abordar esses usuários não apenas como portadores de dependência química, mas, sim, como agentes sociais, que participam de relações em um contexto capaz de influenciá-los nas suas características e atitudes. Ao propor respostas às demandas em saúde, é eficaz mobilizar diferentes disciplinas do conhecimento e diferentes setores da sociedade para que as ações, construídas coletivamente, possam ter impacto. Nesse processo, os usuários que apresentam a demanda em saúde precisam estar constantemente engajados nessa construção, a qual se refere principalmente à sua vida, à sua família e às suas condições de vida.

Ressalta-se a percepção demonstrada por alguns profissionais, na qual o usuário é entendido como um ser complexo, inserido em uma realidade também complexa: [...] daí eu consigo ver como essa integralidade é complexa, porque o teu conhecimento muitas vezes não é suficiente para conseguir resolutividade com aquele paciente [...] (TS01).

A proposta pensada para vencer os desafios para efetivar uma assistência integral à saúde começa pela reorganização dos processos de trabalho na rede básica, e vai somando-se a outras ações assistenciais. ${ }^{13}$ A construção da integralidade do 
cuidado supõe a redefinição de práticas, no sentido de se criar vínculos, acolhimento e autonomia que valorizem as subjetividades inerentes ao trabalho em saúde e às necessidades singulares dos sujeitos, como pontos de partida para qualquer intervenção, construindo a possibilidade do cuidado centrado no usuário. ${ }^{14}$ Exercer a integralidade passa pela necessidade de repensar práticas e conformações dos serviços públicos de saúde, nas quais os usuários devem participar, considerando aspectos objetivos e subjetivos de suas vidas.

\section{A integralidade como articulação das formas de cuidar}

Nesta subcategoria, destaca-se uma situação na qual algumas Agentes Comunitárias de Saúde (ACSs) protagonizaram a realização de atividades educativo-recreativas com adolescentes da comunidade, no intuito de prevenir dependência química, principalmente de crack. Essa atividade proporcionava melhores condições ao desenvolvimento e afirmação desses adolescentes, em sua individualidade e sociabilidade, em uma fase peculiar de suas vidas. A iniciativa das ACSs revela a capacidade de percepção dessas profissionais quanto às necessidades da comunidade.

Destaca-se a percepção de alguns profissionais acerca da integralidade no sentido de articulação das formas de cuidar, como as seguintes falas: [...] compreende desde realizar prevenção, promoção, tratamento e reabilitação em saúde [...] (TS02); [...] é promover a saúde da comunidade [...] (TS05).

A compreensão e o exercício da integralidade, como articulação entre as diferentes dimensões do cuidado (promoção, prevenção, tratamento e reabilitação) em saúde, refere-se à prática de um cuidado integrado em saúde, devendo contemplar, em suas expressões, a demanda e a necessidade dos usuários, procurando identificá-las da maneira mais equânime possível. Em um conceito da integralidade é previsto que, de forma articulada, sejam ofertadas ações de promoção da saúde, prevenção dos fatores de risco, assistência aos danos e reabilitação - segundo a dinâmica do processo saúde/doença. ${ }^{6}$

Identificou-se na ESF um apanhado de ações que contemplam as diferentes dimensões do cuidado no SUS. No entanto, era perceptível a inclinação à realização de ações com caráter preventivo-assistencial, em relação às ações de promoção da saúde. Essa configuração pode ser associada à tendência da lógica assistencial da atenção básica no Brasil, presente no cotidiano dos serviços, na qual ainda são priorizados aspectos preventivos e de reabilitação/acompanhamento de algumas enfermidades específicas, como Hipertensão Arterial Sistêmica e Diabetes, também com intuito de prevenir agravos. Essa postura pode ser explicada a partir de uma abordagem economicista da saúde, na qual se investe em ações com intuito de prevenir agravos geradores de gastos maiores. Essa opção faz parte de um planejamento necessário à sustentação econômica do sistema de saúde. Sua realização não é, por si só, ruim. No entanto, torna-se incompatível com a integralidade, no momento em que se restringe a tais ações. Uma situação comum na ESF refere-se à realização do exame citopatológico de colo de útero. Essa prática é muito estimulada e de grande importância epidemiológica no âmbito da atenção básica. Foi observado que mediante um resultado alterado do exame, em situações nas quais a mulher necessitava de tratamento especializado, realizado por um ginecologista, por exemplo, ela teria de esperar meses pelo atendimento. Tal postura dos serviços de saúde nega o exercício da integralidade, sendo seletiva nas possibilidades que oferece, não respondendo à demanda do usuário, pois oferece diagnóstico, mas não o tratamento adequado.

Percebe-se uma tendência histórica, na organização dos serviços públicos de saúde no Brasil, em se separar ações de promoção e prevenção das ações propriamente assistenciais. Essa tendência, oficializada nos anos em que existiam o Instituto Nacional de Assistência Médica da Previdência Social (INAMPS), com caráter assistencial, e os Centros de Saúde, com caráter preventivo, sobrevive ainda hoje no cotidiano dos serviços de saúde. A integralidade seria exercitada, nesse contexto, na medida em que as ações assistenciais se articulassem às ações preventivas e de promoção da saúde, além de haver uma abertura dos profissionais a outras necessidades não ligadas necessariamente à doença. ${ }^{6}$

Outra reflexão pertinente à discussão referese à compartimentalização das práticas no contexto do processo de trabalho desta ESF. Observouse uma dificuldade acentuada na realização de práticas que envolvam e articulem as diferentes dimensões do cuidado nos momentos de encontro entre trabalhadores da saúde e usuários. Diante disso, a Promoção da Saúde representaria uma ampliação de práticas, aproximando-se do conceito da integralidade, na medida em que melhora as condições de vida da população e possibilita a sinergia de potencialidades para a efetividade do cuidado. Assim, age procurando identificar e 
enfrentar os determinantes do processo de saúde/ doença, buscando transformá-los favoravelmente na direção da saúde. ${ }^{15}$

Diante disso, alude-se à necessidade de uma avaliação constante da organização e orientação dos serviços de saúde, conectada às profundas iniquidades sociais existentes no país, cujo reflexo está presente nos indicadores de saúde. Para tanto, o planejamento de ações capazes de agregar outras disciplinas e setores do serviço público, bem como representantes da sociedade civil pode criar possibilidades reais e efetivas para responder à demanda social em saúde.

\section{A integralidade como identificação e atendimento das necessidades em saúde}

A integralidade, nesta subcategoria, refere-se à capacidade da equipe de ESF para identificar e conseguir atender as demandas em saúde construídas por usuários, famílias e comunidade. Isso é expresso a partir das seguintes falas: [...] assistir o usuário, sua família e comunidade, levando em consideração suas necessidades de atenção em saúde, suas expectativas como atores sociais e suas demandas enquanto cidadãos [...] (TS02); [...] atender em todas as necessidades que cabe à parte da saúde [...] (TS03); [...] procurar suprir algumas necessidades naquele usuário que está procurando atendimento [...] (TS01).

Percebe-se, nessas falas, a consciência de alguns trabalhadores da equipe em procurar conhecer e atender as demandas em saúde dos usuários. Reitera-se que a integralidade possui seu suporte de sustentação e efetivação nas necessidades em saúde dos indivíduos e grupos sociais. ${ }^{16}$

Observou-se a existência de uma grande demanda espontânea, por parte da comunidade, por consultas médicas. Em muitos casos integrantes dessa demanda, os usuários não necessitavam dos cuidados específicos do trabalhador médico, mas, sim, demandariam acolhimento e a escuta de suas necessidades, cuja prática poderia ser realizada por todos os integrantes da equipe de ESF. Outro fato relevante refere-se às pessoas que procuravam a USF diariamente com as mesmas queixas. Isso expressa certa dificuldade, por parte dos trabalhadores, em perceber as reais necessidades que os usuários tentavam apresentar. A fala a seguir demonstra isso: [...] é que eles sempre querem mais, que tu dês, eles nunca estão satisfeitos [...] (TS06).

Nota-se a carência de elementos teóricos, práticos e estruturais, por parte da equipe como um todo, para exercitar a escuta e compreender o que essas pessoas necessitavam. Tal constatação ganha respaldo na observação de práticas em que o modelo médico-centrado, voltadas ao fator biológico, ainda possuía presença imperativa. Nessas práticas, procurava-se resolver os problemas com medicações, exames e procedimentos. Priorizavam-se as tecnologias leve-duras (normalizadas, procedimento-centradas) em detrimento de tecnologias leves, como a escuta, o acolhimento, o vínculo. ${ }^{17}$ Em muitas situações, as últimas são mais resolutivas que as primeiras, devendo-se, no entanto, utilizá-las em complementaridade. Os usuários, em geral, reclamam não da falta de conhecimento tecnológico no seu atendimento, mas sim da falta de interesse e de responsabilização dos diferentes serviços em torno de si e do seu problema. ${ }^{18}$

Essas afirmações sugerem a necessidade de reavaliação de condutas e prioridades no cuidado em saúde. Os trabalhadores, na condição de equipe de saúde responsável e comprometida, precisam desenvolver habilidades no sentido de criar momentos que impulsionem o desvelo das reais necessidades do usuário. Para tal, deve-se estar disposto à escuta, ao encontro, à responsabilização e ao vínculo. Para isso, os trabalhadores precisam estar motivados para o trabalho, com estabilidade e segurança em seu vínculo empregatício, e participando ativamente de um processo de educação permanente, no qual as experiências e práticas cotidianas devem conduzir uma discussão teórica e empírica capaz de subsidiar práticas de cuidado mais conectadas ao usuário e, por isso, mais efetivas.

Outra observação relativa ao relacionamento entre trabalhadores e usuários diz respeito às consultas realizadas por integrantes da equipe, nas quais foi visível o estabelecimento de uma relação na qual o trabalhador seria dotado de saber, devendo transmiti-lo ao usuário. Encontravam-se muitos usuários calados, receosos em manifestar suas dúvidas, desejos ou contraposições, em função do medo de represálias, ou de que lhes fosse negado atendimento. Quando algum usuário mostravase questionador, ou apenas demonstrava suas vontades ou sua forma de perceber a situação em pauta, era rotulado como um usuário "difícil", "incômodo", "que não sabia o seu lugar".

Pôde-se perceber que poucas situações de cuidado se caracterizaram como verdadeiros encontros onde os anseios dos usuários foram escutados. $\mathrm{O}$ pequeno espaço de tempo para esses momentos, em função da demanda de trabalho e da concepção ainda arraigada nos trabalhadores, da superioridade de seu saber com relação ao saber do usuário, cons- 
tituem os fatores mais evidentes que influenciam a não realização desse encontro e, em consequência, a realização de um cuidado não integral.

Alguns profissionais referiram que a integralidade deveria ser exercitada como um encontro entre sujeitos, como segue: [...] eu acho que é isso, saber dividir as coisas [...] as experiências com o outro, saber se ceder um pouco para o outro [...] (TS06); [...] levar em consideração suas expectativas enquanto atores sociais e suas demandas enquanto cidadãos [...] (TS02).

Cabe lembrar o efeito dialógico dos elementos constitutivos da integralidade. Estes deveriam produzir a polifonia, caracterizada pela escuta das vozes dos usuários que buscam cuidado em saúde. Esses elementos compreendem, portanto, a atenção direcionada aos usuários e a incessante busca pela resolutividade de suas demandas em saúde. ${ }^{3}$ As práticas de cuidado devem assumir a forma de um encontro entre trabalhadores e usuários, no qual o trabalhador, apesar das limitações externas, deverá fazer um esforço para prestar um cuidado integral. ${ }^{6}$

A aproximação de diferentes saberes e modos de ver o mundo é o que realmente caracteriza um encontro entre sujeitos. Muitas vezes a construção compartilhada de decisões e planos não ocorre porque apenas o saber técnico-científico do trabalhador é considerado nesse processo. Em tais situações, não existe a preocupação em considerar os anseios, a cultura, o saber e o modo de ver o mundo do usuário. Esses momentos dificilmente irão resultar na produção de um cuidado integral, pois foram concebidos apenas por uma das partes, o que compromete a pactuação e realização de ações que impulsionem a construção conjunta de práticas geradoras de saúde.

\section{A integralidade como esforço da equipe em produzir saúde}

A integralidade surge aqui com um sentido que pode parecer óbvio, mas que em muitos momentos ganha papel secundário nos serviços de saúde. No período de observação, pôde-se perceber, em algumas ocasiões, que o trabalho dos profissionais acabava por ter um fim em si, sem estar direcionado à produção da saúde da comunidade. Nesse aspecto, infere-se que a falta de comprometimento com a saúde da população, a frustração e o desânimo podem ser considerados fatores que influenciem nessa situação. Notava-se que a origem desses sentimentos, nos trabalhadores da equipe, parecia estar associada à formação profissional de seus integrantes, na qual o compromisso real com a produção da saúde por vezes ficava distorcido.

Observou-se que a prática desenvolvida cotidianamente privilegiava as tecnologias leve-duras para a realização do cuidado, sendo requisitado um número elevado de exames diagnósticos, muitos encaminhamentos a especialistas e utilização desenfreada de medicações. O único integrante da equipe que verbalizou a produção da saúde como exercício da integralidade foi um profissional de secretaria/recepção, que disse: [...] é união, profissionais que trabalham juntos com um objetivo em comum, que é a saúde da comunidade [...] (TS05).

O objetivo principal da equipe de ESF (a produção de saúde) é distorcido e legitimado por uma lógica que interessa a setores que dominam o complexo médico-industrial e, em consequência, ao poder econômico. ${ }^{17}$ Os resultados desse modelo, baseado na especialidade e na diminuição crescente da capacidade de cada profissional resolver problemas, têm sido tratamentos cada vez mais longos, envolvendo inúmeros especialistas, com custos crescentes, com mais sofrimento e restrições impostas aos usuários, e com uma perda da visão integral do usuário que necessita de cuidados em saúde. Assim, os compromissos passaram a ser indiretos, com a saúde em geral, com a população, com o saber, com a coletividade, distanciando-se dos agentes/usuários/clientes ou parcela real da população. ${ }^{19}$

Esses aspectos puderam ser observados a partir da limitada capacidade de resolutividade das práticas realizadas pelos trabalhadores. Foram visualizadas várias situações nas quais uma investigação condizente com a clínica ampliada seria capaz de resolver situações e problemas de saúde no âmbito da própria ESF. No entanto, esse olhar apurado não era realizado em boa parte das abordagens com os usuários, resultando em encaminhamentos para serviços de referência, geralmente de média complexidade. Essa situação reflete a distorção dos fins da saúde, processo que se inicia na formação acadêmica do trabalhador, e é reiterado ao longo do exercício da profissão, por meio da publicidade e de pesquisas tendenciosas, financiadas pelo complexo médico-industrial.

\section{A integralidade como cuidado a grupos específicos}

A integralidade compreendida como cuidado a grupos específicos pode ser exemplificada com duas situações observadas, capazes de ex- 
pressar cuidado integral e não integral. A primeira refere-se a um grupo de hipertensos e diabéticos, organizado em uma comunidade adscrita à USF estudada. A própria definição do grupo já se apresentava taxativa, rotulando seus participantes. $\mathrm{Na}$ reunião mensal desse grupo, a principal atividade era restrita à distribuição de medicamentos e à aferição de pressão arterial. Era visualizada nesses usuários apenas a sua especificidade, nesse caso, a doença que os levou a serem convidados a participar das atividades do grupo.

Em contrapartida, em outra comunidade, também adscrita a essa USF, existia um grupo de saúde aberto a participantes de ambos os sexos, no qual participavam apenas mulheres. Nos encontros desse grupo eram discutidos diversos aspectos da saúde, envolvendo-se neles a saúde da mulher, que era a especificidade das participantes, e a aferição de pressão arterial, pois algumas delas eram portadoras de Hipertensão Arterial Sistêmica (HAS). Nesses encontros ocorriam momentos de troca nos quais se falava da vida, de suas dificuldades, de suas alegrias e das maneiras para melhorá-la. Procurava-se produzir saúde conjuntamente, a partir da vida das pessoas e não apenas a partir da abordagem de suas doenças e/ ou especificidades.

A integralidade aparece nesta subcategoria como o cuidado realizado com grupos alvo de políticas específicas, tais como pessoas portadoras de HAS, mulheres, idosos, entre outros tantos. Exercitar a integralidade no cuidado com esses usuários significa percebê-los e abordá-los não apenas como o fator que os levou a ser objeto da política. Pelo contrário, é compreender esses indivíduos como seres complexos, inseridos em um contexto e que possuem determinada especificidade, a qual é apenas mais um dos aspectos que constitui essas pessoas. ${ }^{6}$ Essa perspectiva da integralidade nos convida a repensar a maneira como estão organizadas as práticas de cuidado e de gestão destinadas às pessoas que vivenciam condições específicas de saúde, de modo a responder as suas necessidades as quais se expressam no seu viver cotidiano. ${ }^{21}$

\section{CONSIDERAÇÕES FINAIS}

Ao serem abordados os saberes e práticas de cuidado integral de uma equipe de ESF constatouse a existência de diferentes sentidos para a integralidade, percebidos nas entrevistas, anotações em prontuários e observação das práticas dos sujeitos da presente pesquisa. Verificou-se o sentido de integralidade como percepção das diferentes dimensões e da complexidade do usuário, de forma que os integrantes da equipe concebem-no como um ser dotado dessas variadas dimensões. Ao mesmo tempo, foram percebidas situações em que era dada ênfase à atenção restrita a sistemas do corpo humano, cujo objetivo principal restringiase à resolução dos sintomas do usuário, sem as conexões com suas dimensões em seu contexto de vida, bem como práticas profissionais isoladas, mesmo trabalhando em equipe. A compreensão da complexidade dos usuários e seus contextos foi identificada em situações nas quais emergiu a relevância do olhar nas interações que articulam o viver dos usuários com seus problemas de saúde.

A análise dos dados obtidos denota que a efetivação da integralidade depende da construção de novas práticas, orientadas a um cuidado ampliado, exercido na perspectiva da complexidade dos usuários e de suas condições de vida. Evidencia-se a necessidade de realização de um esforço, que deve partir inicialmente dos trabalhadores e gestores da saúde, no intuito de viabilizar uma nova forma de organizar os serviços de saúde, estruturada a partir de um processo efetivo de educação permanente. Repensar práticas em saúde, buscando orientá-las pela lógica da integralidade, agrega a necessidade de mudar muitas concepções e atitudes nas instituições relacionadas ao assunto. Essa iniciativa é desafiada pelos obstáculos construídos pelas estruturas de interesses, especialmente econômicos, a fim de evitar tais mudanças. Porém, a exemplo da luta pela reforma sanitária, a busca pela reorganização dos serviços, como forma de propor novas práticas, voltadas não apenas à assistência médica e à prevenção de doenças, deve ser compreendida pelos trabalhadores da saúde, juntamente com as instituições formadoras, movimentos sociais, usuários e setores do próprio governo, como um desafio da saúde coletiva na atualidade.

\section{REFERÊNCIAS}

1. Luz MT. Demanda em saúde: construção social no campo multidisciplinar da saúde coletiva. In: Pinheiro R, Mattos RA. Gestão em redes: práticas de avaliação, formação e participação na saúde. Rio de Janeiro (RJ): CEPESC-IMS/UERJ-ABRASCO; 2006. p. 27-31.

2. Brasil. Centro de Documentação e Informação. Coordenação de Publicações. Constituição da Republica Federativa do Brasil. Brasília; 2004.

3. Pinheiro R, Guizardi FL. Cuidado e integralidade: por uma genealogia de saberes e práticas. In: 
Pinheiro R, Mattos RA. Cuidado: as fronteiras da integralidade. Rio de Janeiro (RJ): IMS/UERJ/ CEPESC/ABRASCO; 2006. p.21-36.

4. Santos M. Por uma outra globalização: do pensamento único à consciência universal. Rio de Janeiro (RJ): Record; 2001.

5. Mattos RA. Princípios do Sistema Único de Saúde (SUS) e a humanização das práticas de saúde. Interface Comunic., Saude Educ. 2009 Abr-Jun; 13(S1):771-80.

6. Pinheiro R, Mattos RA, organizadores. Os sentidos da integralidade na atenção e no cuidado à saúde. $6^{\mathrm{a}} \mathrm{ed}$. Rio de Janeiro (RJ): IMS/UERJ - ABRASCO; 2006.

7. Ministério da Saúde (BR). Portaria n. 648 de 28 de março de 2006. Regulamenta as ações de Atenção Básica em Saúde no SUS. [acesso 2008 Jan 16]. Disponível em: http://dtr2001.saude.gov.br/sas/ PORTARIAS/Port2006/GM/GM-648.htm

8. Víctora CG, Knauth DR, Hassen MNA. Pesquisa qualitativa em saúde: uma introdução ao tema. Porto Alegre (RS): Tomo Editorial; 2000.

9. Minayo MCS. O desafio do conhecimento: pesquisa qualitativa em saúde. São Paulo (SP): Hucitec; 2008.

10. Ministério da Saúde (BR), Conselho Nacional de Saúde, Comissão Nacional de Ética em Pesquisa. Resolução n ${ }^{\circ} 196$ de 10 de outubro de 1996: diretrizes e normas regulamentadoras de pesquisa envolvendo seres humanos [online]. Brasília (DF): MS; 1996 [acesso 2006 Dez 13]. Disponível em: http:/ / www. ufrgs.br/bioetica/res196/96.htm.

11. Severo SB, Seminotti N. O sujeito e a coletividade: um caminho transdialógico na saúde coletiva. Rev Psicologia USP. 2007 Dez; 18(4):53-78.
12. Mioto RCT. Trabalho com famílias: um desafio para os assistentes sociais. Rev Virt Textos e Contextos. 2004 Dez; 3(3):1-14.

13. Franco TB. Produção do cuidado e produção pedagógica: integração de cenários do sistema de saúde no Brasil. Interface. 2007 Set-Dez; 11(23):427-38.

14. Silva, KL; Sena RR. Integralidade do cuidado na saúde: indicações a partir da formação do enfermeiro. Rev Esc Enferm USP. 2008 Mar; 42(1):48-56.

15. Buss PM; Pellegrini Filho A. A saúde e seus determinantes sociais. Physis Saúde Colet. 2007 Jan-Abr; 17(1):77-93.

16. Cecílio LCO. As necessidades de saúde como conceito estruturante na luta pela integralidade e equidade na atenção à saúde. In: Pinheiro R, Mattos RA, organizadores. Os sentidos da integralidade na atenção e no cuidado à saúde. $6^{\mathrm{a}}$ ed. Rio de Janeiro (RJ): IMS/UERJ - ABRASCO; 2006. p.113-27.

17. Merhy EE. Todos os atores em situação na saúde disputam a gestão e produção do cuidado. In: Merhy EE. Saúde: a cartografia do trabalho vivo. $3^{\text {a }}$ ed. São Paulo(SP): Hucitec; 2007. p. 149-78.

18. Merhy EE. Ato de cuidar: alma dos serviços de saúde. In: Merhy EE. Saúde: a cartografia do trabalho vivo. $3^{a}$ ed. São Paulo (SP): Hucitec; 2007. p. 115-33.

19. Campos GWS. Saúde paidéia. $3^{a}$ ed. São Paulo (SP): Hucitec; 2007.

20. Thaines GHLS, Bellato R, Faria APS, Araújo LFS. A busca por cuidado empreendida por usuário com diabetes mellitus - um convite à reflexão sobre a integralidade em saúde. Texto Contexto Enferm. 2009 Jan-Mar; 18(1):57-66. 